\title{
Breast Centers Revisited - a Critical Perspective
}

\author{
Michael Gnant \\ Department of Surgery, Medical University of Vienna, Austria
}

For more than a decade, at least some standard operating procedures for certification of breast units and breast centers have been generally accepted. In my opinion that justifies a critical review of the success of these initiatives. Clearly, quality assurance and control mechanisms are mandatory elements of modern patient-oriented medicine, and in principle, giving both patients and health care providers reasonable means of guidance on what should be considered state of the art in diagnosis and treatment of breast diseases is both reasonable and necessary. There are, however, several observations that are suited to question whether the current strive for 'centerization' is actually the right means to achieve those laudable aims:

First, there are several types of 'breast centers', basically separated by their degree of certification. Some centers have achieved certification by an official body like the European Society of Mastology (EUSOMA). There are, however, also 'self-declared' breast centers, whose main achievement consisted in mounting a respective nameplate on their doors, maybe accompanied by a press release. Obviously, the process of certification is a necessary prerequisite for a breast center to be accepted scientifically, however, for patients it may be difficult - if not impossible - to distinguish centers that underwent a formal certification process from those that did not. Sometimes, breast centers are founded or declared for the sole purpose of marketing or increasing patient referrals, and so far such abuse is tricky to detect and virtually impossible to prohibit. In most countries, generally accepted mechanisms of action or punishment for such wrongdoing are lacking, both juridical and factual.

Second, there is still a lack of a generally accepted set of rules. The guidelines of EUSOMA may be the most widely accepted throughout Europe, and the guidelines of the German Society of Senology are popular in German-speaking countries. There are, however, differences, and the rules are not superimpos- able and in some respects not even similar to other international guidelines, such as accepted consensuses (NIH, NCCN, St. Gallen). For those who want to certify their breast unit it is often a considerable difficulty to sort out these differences and the first necessary decision will be according to which regulations the certification should take place. An international consensus of even a uniform requirement by a governing body (e.g. the European Union) could assist in building a coherent and understandable set of rules.

Third, the process of certification is sometimes described as overly bureaucratic. A growing number of so-called quality assurance specialists and certification consultants basically make their livings from the fact that the processes involved with the certification of a breast center are almost impossible to understand for ordinary physicians without particular knowledge of or even increased interest In process management and optimization. This is not to say that process quality should not be a subject of such certification and review initiatives. However, if colleagues tell me that the time they need to pick up the phone is recorded during certification tests, I cannot help thinking that this may be overdoing it. On the other hand, there is astonishingly little emphasis on actual outcome measures in some of these certification processes.

Clearly, reasonable certification involves establishment of an ongoing process of quality control rather than a one-time assessment. To my mind, the certification rules of the German Society of Senology have to be most applauded for their recertification mechanism after 3 years. Other certification systems lack such necessary re-validation, which ideally should be repeated indefinitely at regular intervals.

In fact, there are differing perceptions among physicians in and outside breast centers about their actual necessity. Those who groan under pressure of their certificators may wish that they had never started the process. Those who are not yet certified usually voice their doubts about the validity of the sys-

\begin{tabular}{llll}
\hline KARGER & ( ) 2006 S. Karger GmbH, Freiburg & & Univ. Prof. Dr. med. Michael Gnant \\
Fax +49 7614520714 & Accessible online at: & Medizinische Universität Wien \\
$\begin{array}{ll}\text { E-mail Information@Karger.de } \\
\text { www.karger.com }\end{array}$ & www.karger.com/brc & Universitätsklinik für Chirurgie \\
& & Währinger Gürtel 18-20, 1090 Wien, Austria \\
& & Tel. +431 40400-5646, Fax -6807 \\
& & E-mail michael.gnant@meduniwien.ac.at
\end{tabular}


tem, a position that immediately changes after they get their final green light: from that very moment on they think that no patient should be treated outside a certified center.

Can we really assume that the process of certification is working? A simple example: Currently (May 2006), there are more than 100 certified breast centers in Germany and just 3 of them in Austria. Does this difference actually reflect a similar difference in the standard of care? This is unlikely, as in contrast, participation in clinical trials (by the way, a most effective way to provide quality assurance) is traditionally higher in Austria by a factor of 10, if assessed on a nation-wide basis.

After all these years of publishing guidelines and setting up certification systems, the scientific community should now enter a phase of validating the validation systems. What has changed? Have patient streams actually been redirected towards quality-controlled providers? Have outcome parameters changed within those institutions that have been certified and can that be proven by data? Have treatment habits improved and are they reflecting the standard of care as defined by most recent scientific achievements? Have the certification systems led to increased participation of patients in clinical trials, and what should be a logical goal and consequence of the process? How can we assist physicians and other health care professionals who want to observe scientifically evidenced standards and become certified breast centers with their teams but are intimidated by the bureaucracy and cost involved?

In this issue of BREAST CARE, you will find several articles about how it could work. These more than successful examples of most distinguished breast centers prove that in principle the idea is right. As with many ideas, it is what was realized in some places that brought serious concerns and some flaws. While the details of certification systems must be improved, the principles of quality management and patient-oriented optimization of medical processes must neither be questioned nor abused, not even by certification systems.. 